\title{
Experience of the Irish physician associate role: PA and supervising consultant perspectives
}

\author{
Lea R. Hix*1, Susan M. Fernandes ${ }^{1}$, Pauline Joyce $^{2}$ \\ ${ }^{1}$ School of Medicine, Stanford University, USA \\ ${ }^{2}$ School of Medicine, Royal College of Surgeons in Ireland, Ireland
}

Received: June 4, 2020

DOI: $10.5430 /$ ijh.v7n1p18
Accepted: August 12, 2020

Online Published: October 11, 2020

\begin{abstract}
Background: The physician associate/assistant (PA) role was introduced into the Irish healthcare system in 2015 when four PAs from North America were recruited to work in Ireland as part of a two-year pilot program. In parallel, the Royal College Surgeons in Ireland (RCSI) began its own PA program in January of 2016 and has graduated 25 PAs. To date, there is little published on the few Irish-trained PAs. This study seeks to share initial experiences with the PA profession in Ireland.

Methods: This descriptive phenomenological study explores the newly implemented PA role in Ireland through semi-structured, one-to-one interviews with five PAs and their supervising consultants in Dublin, Ireland. Questions centered on the PA scope of clinical practice, satisfaction with the role, acceptance by the medical team, and integration into the Irish healthcare system.

Results: Six themes were identified from the interviews: continuity of patient care, flexible scope of practice, lack of role clarity, complementary to the medical team, regulation and prescribing challenges, and the emerging role of the PA.

Conclusions: The development of the PA role is in its infancy in Ireland, but this study suggests that they fill an important role by providing continuity of care to both patients and the medical team. Currently, there are significant challenges imposed by a lack of regulation of the PA profession and the inability to prescribe. However, PAs in Ireland appear to enjoy their work, are valued by their team members, and have great potential to expand throughout Irish healthcare.
\end{abstract}

Key Words: Physician assistant/associate, Consultant, Perspective, Interviews, Integration, Task-Shifting, Ireland

\section{INTRODUCTION}

The physician assistant (PA) role first began in the United States in the mid-1960s, when experienced military medics back from war were admitted for additional training in the first PA program to help address a shortage in the American healthcare workforce. ${ }^{[1]}$ The profession has since exploded in the US, with PAs practicing in every state, medical specialty, and clinical setting - reaching almost 140,000 certified PAs throughout the country by the end of 2019. ${ }^{[2]}$ PAs in the US are authorized to diagnose illness, create treatment plans, order and interpret diagnostic studies and imaging, prescribe medication, and assist in surgery. ${ }^{[3]}$ PA-like roles have been adapted in many countries globally, known as physician associates or clinical assistants/associates/officers in some. These countries include Canada, the UK, Ireland, Germany, the Netherlands, Israel, India, South Africa, Kenya, and more. ${ }^{[4-6]}$ PAs have functioned in the Canadian military since the mid-1980s and in civilian settings since 2008, ${ }^{[7]}$ now working in Ontario, Manitoba, Alberta, New Brunswick, and Nova Scotia. ${ }^{[8]}$ The role was introduced to the UK in 2003 but has grown exponentially since about $2016,{ }^{[9]}$ and following a 2017 announcement will soon be an officially

*Correspondence: Lea R. Hix; Email: 1hix@ stanford.edu; Address: Stanford University, Office of PA Education, Stanford, CA 94305, USA. 
regulated profession in the UK. ${ }^{[10,11]}$ PAs were introduced to Germany in 2005 but have been experiencing a spike in growth in recent years, and function to assume delegable medical tasks to help address physician shortages. ${ }^{[12]}$ Many Sub-Saharan African countries have similar non-physician clinician roles characterized by variable levels of formal training working to address health workforce shortages, mostly in rural areas. ${ }^{[6]}$ The PA is expanding globally, with some differences in scopes of clinical practice and with varying degrees of regulation and prevalence in each country that has adapted the role.

The PA role was introduced into the Irish healthcare system in 2015 when four PAs from North America were recruited to work in one hospital in Ireland as part of the two-year pilot project with the Irish Department of Health. ${ }^{[13]} \mathrm{Nu}-$ merous factors are driving the implementation of PAs in Ireland, including workforce shortages, a need for improved continuity of care for patients, and the European Working Time Directive. ${ }^{[13]}$ Compared to other countries, Ireland's medical teams rely more heavily on "non-consultant hospital doctors," commonly referred to as "junior doctors," for the delivery of care. ${ }^{[13]}$ Junior doctors include all physicians in training, from interns to senior residents, whose training is characterized by rotating to hospitals throughout the country every 3, 6, or 12 months. ${ }^{[14]}$ Large-scale team changeovers of junior doctors occur in January and July, which can be disruptive to continuity of patient care. ${ }^{[13]}$ This is aggravated by general workforce shortages, with fewer junior doctors entering postgraduate training programs and more doctors emigrating out of Ireland. ${ }^{[15]}$ Additionally, PAs are seen as a way to improve compliance with the European Working Time Directive, which since 2004 has limited doctors' working hours to an average of 48 hours per week. ${ }^{[16]}$

Many Irish surgeons carry out their specialist surgical training in the United States and Canada and return to Ireland with a good understanding of the PA role and what it can offer the health service. In 2015, the opportunity arose to pilot the profession within the surgical directorate of Beaumont Hospital, a large teaching hospital in Dublin. Alongside the pilot project, the Royal College Surgeons of Ireland (RCSI) (the hospital's academic link) began its own Master of Science (MSc) in Physician Associate Studies program in January 2016. ${ }^{[17]}$ The program has already graduated 25 PAs who now work in a variety of specialties in numerous hospitals in Dublin as well as in other cities throughout Ireland. Another 10 students are expected to finish their training in December 2020. Because the role is so new, very little published information exists on these few Irish-trained PAs ${ }^{[18]}$ or the impact of the PA role in Ireland thus far. To date, most of the focus has been on the patient perspective, ${ }^{[19,20]}$ however more information is needed from the PA and supervising physicians' perspectives. Given this, the current study uses in-person semi-structured interviews with PAs and supervising consultants in Dublin and seeks to better understand the Irish PA scope of clinical practice, acceptance by physicians, and integration into the Irish healthcare system.

\section{METHODS}

This descriptive phenomenological ${ }^{[21]}$ study explores the newly-implemented PA role in Ireland by interviewing hospital-based surgical PAs and supervising consultants working in Dublin. The goal of phenomenological enquiry is to fully describe the meaning of lived experiences. ${ }^{[22]}$

\subsection{Data collection}

This study explored the Irish PA role through interviews with five PAs and their supervising consultants working in Dublin, Ireland. Participants were purposively sampled from a known pool of PA graduates and were invited to the study via an emailed Letter of Invitation with all 10 agreeing to participation. Nine of the interviews took place within 1 week on-site in Dublin, and 1 interview was held 4 months later remotely via phone due to scheduling conflicts. Semi-structured oneto-one interviews focused on participants' experiences of the PA scope of practice, job satisfaction, acceptance by consultants and the rest of the medical team, and their integration into the Irish healthcare system. Interviews were audio recorded with written consent. Hospital-based ethics and Stanford University IRB approval (FWA \#00000935) were obtained for the study.

\subsection{Data analysis}

Interview audio was transcribed. Participants were anonymized using the labels "PA 1-5" and "Consultant V, W, X, Y, Z." The transcripts were coded and categorized with NVIVO using a hybrid inductive-deductive approach and then analyzed via thematic analysis to identify key themes. ${ }^{[22]}$ A second researcher reexamined and confirmed these six main themes identified.

\section{Results}

Six main themes were identified (see Table 1): 1. Continuity of patient care, 2. Flexible scope of practice, 3. Lack of role clarity, 4. Complementary to the medical team, 5. Regulation and prescribing challenges, 6 . Emerging role of the PA.

\subsection{Continuity of patient care}

According to the PAs and consultants interviewed, Irish PAs serve a needed role of care continuity for hospital staff, their consultant, and patients while the junior doctors, who make up a large part of each medical team, rotate every 3,6 , and 
12 months. PAs are especially useful in July when all members of the team change except for the consultant and the physician associate.

PAs allocated to the various teams were bringing the new teams around, introducing them to the patients, bringing them up to speed to where their treatment was at. The continuity of care was suddenly there that wasn't there before. So that was a great moment for us. (Consultant V)

Table 1. Thematic summary of interview data

\begin{tabular}{|c|c|}
\hline Themes & Illustrative Interview Quotes \\
\hline $\begin{array}{l}\text { 1. Continuity of patient care } \\
\text { Medical team has continuity while junior doctors rotate } \\
\text { PAs are a stable liaison between clinical teams and departments } \\
\text { Returning patients can see the same provider at subsequent visits }\end{array}$ & $\begin{array}{l}\text { In the second week of July, we have our rotation - and at } \\
\text { that rotation, everybody on the team changes except for } \\
\text { the consultant and me, the PA... So everybody is new to } \\
\text { the service and they're trying to figure out what this } \\
\text { service needs. (PA 5) }\end{array}$ \\
\hline $\begin{array}{l}\text { 2. Flexible scope of practice } \\
\text { PAs can mitigate staff shortages } \\
\text { PAs can assume responsibilities according to fluctuating team needs } \\
\text { PAs develop more responsibility with more experience and time on } \\
\text { their team } \\
\text { PAs can positively impact a variety of domains within the service }\end{array}$ & $\begin{array}{l}\text { So your autonomy is based on what the consultant needs, } \\
\text { what the team needs at the time, and where you fit in. (PA } \\
\text { 2) }\end{array}$ \\
\hline $\begin{array}{l}\text { 3. Lack of role clarity } \\
\text { Some supervising consultants had uncertainty about the PAs' } \\
\text { limitations } \\
\text { It can be difficult to find a balance between using the PA } \\
\text { administratively and clinically } \\
\text { There is a lack of communication between teams employing PAs } \\
\text { Other physicians' lack of knowledge on the PA role can affect the } \\
\text { PA's practice }\end{array}$ & $\begin{array}{l}\text { Maybe it's just me who's unclear, but maybe we need to } \\
\text { be clearer in Ireland about what PAs can and can't do. } \\
\text { (Consultant Z) } \\
\text { Educating other people on what my scope is. That would } \\
\text { be the only thing I would want to change... people } \\
\text { knowing what it is I'm able to do, what I'm signed off to } \\
\text { do, what my consultant has agreed that I can do. (PA 4) }\end{array}$ \\
\hline $\begin{array}{l}\text { 4. Complementary to the medical team } \\
\text { Perceived positively as an integral member of the team } \\
\text { Complement junior doctors by assuming some tasks allowing them } \\
\text { more surgical training time } \\
\text { PAs help organize patient care to improve daily workflow } \\
\text { Consultants appreciated how the PA would improve efficiency } \\
\text { assisting in surgery }\end{array}$ & $\begin{array}{l}\text { My senior house officers are getting to theater much } \\
\text { more because a lot of the routine work on the wards, in } \\
\text { terms of admissions, in terms of processing patients, } \\
\text { that's being done by the PA and that's freeing up the } \\
\text { surgical trainees to actually do surgical training. } \\
\text { (Consultant X) }\end{array}$ \\
\hline $\begin{array}{l}\text { 5. Regulation and prescribing challenges } \\
\text { The PA role is currently unregulated in Ireland } \\
\text { Delays in care arise as PAs are not authorized to prescribe } \\
\text { medications or order ionizing radiation } \\
\text { PAs discuss treatment plans with their team but prescriptions and } \\
\text { orders involving ionizing radiation must be signed by a doctor } \\
\text { PAs are trained and authorized to order other tests } \\
\text { Consultants had mixed opinions about whether PAs should prescribe }\end{array}$ & $\begin{array}{l}\text { [Patients] can be waiting up to } 30 \text { minutes until one of } \\
\text { the other doctors is free to come and either write the } \\
\text { prescription or order imaging... So it can really delay } \\
\text { things from a time perspective... I'll be hovering in the } \\
\text { corridor waiting for someone to be free, and the poor } \\
\text { patient is just sitting there. (PA 4) }\end{array}$ \\
\hline $\begin{array}{l}\text { 6. Emerging role of the PA } \\
\text { PAs are generally unknown in Ireland and have low visibility in the } \\
\text { medical field } \\
\text { Employers should maintain/improve attractiveness of the PA role } \\
\text { The PA role is expected to continue to evolve and expand in Ireland }\end{array}$ & $\begin{array}{l}\text { Unless you've trained in North America, you don't really } \\
\text { know what a PA is... It's really all around just letting } \\
\text { people know what the role is and how they're here to } \\
\text { help...And that they're here to stay. (Consultant V) }\end{array}$ \\
\hline
\end{tabular}

This continuity allows a PA to be a reliable point of contact for other departments, facilitating communication across the hospital.
Themes

Medical team has continuity while junior doctors rotate

PAs are a stable liaison between clinical teams and departments

Flexible scope of practice

PAs can mitigate staff shortages

PAs can assume responsibilities according to fluctuating team need

PAs develop more responsibility with more experience and time on their team

Lack of role clarity administratively and clinically

There is a lack of communication between teams employing PAs

Other physicians' lack of knowledge on the PA role can affect the

Perceived positively as an integral member of the team

Complement junior doctors by assuming some tasks allowing them more surgical training time

PAs help organize patient care to improve daily workflow

Consultants appreciated how the PA would improve efficiency

Regulation and prescribing challenges

The PA role is currently unregulated in Ireland

Delays in care arise as PAs are not authorized to prescribe medications or order ionizing radiation

PAs discuss treatment plans with their team but prescriptions and orders involving ionizing radiation must be signed by a doctor

PAs are trained and authorized to order other tests

Emerging role of the PA

PAs are generally unknown in Ireland and have low visibility in the medical field

The PA role is expected to continue to evolve and expand in Ireland

\section{Illustrative Interview Quotes}

that rotation, everybody on the team changes except for the consultant and me, the PA... So everybody is new to the service and they're trying to figure out what this service needs. (PA 5)

So your autonomy is based on what the consultant needs, what the team needs at the time, and where you fit in. (PA 2)

Maybe it's just me who's unclear, but maybe we need to be clearer in Ireland about what PAs can and can't do.

Educating other people on what my scope is. That would the only thing I would want to change... people knowing what it is I'm able to do, what I'm signed off to

My senior house officers are getting to theater much more because a lot of the routine work on the wards, in terms of admissions, in terms of processing patients, that's being done by the PA and that's freeing up the surgical trainees to actually do surgical training. (Consultant X)

[Patients] can be waiting up to 30 minutes until one of the other doctors is free to come and either write the prescription or order imaging... So it can really delay things from a time perspective... I'll be hovering in the corridor waiting for someone to be free, and the poor patient is just sitting there. (PA 4)

Unless you've trained in North America, you don't really know what a PA is... It's really all around just letting people know what the role is and how they're here to 
Because I am constantly liaising with different departments within the hospital, and I'm the only one from our service doing that, I've built up a relationship with [other departments] as well... they always know that you're the person that we can call on the service that we know we'll get in contact with. (PA 5)

PA continuity also benefits patient care.

Somebody who's invested in the team and has a long-term attachment to the team gets much more involved in the specifics of how our patient group is being managed. (Consultant $\mathrm{Z}$ )

The PAs interviewed expressed that many of their patients appreciate seeing the same provider for follow up visits over a long period of time, instead of a provider who must continue rotating.

You see patients coming back requesting to see you because you've already gone through their history, you don't have to start from scratch again... I've provided a level of care and communication with that patient where they feel that they're comfortable to voice their concerns or their worries with you. (PA 5)

\subsection{Flexible scope of practice}

Consultants and PAs suggested how the flexibility of the PA role allows PAs to help address shortages of healthcare personnel.

One of the things we have here, that is not such a big issue in North America but certainly is here, is manpower issues... So it's a no-brainer for the role of the PA, and the Irish healthcare system desperately needs PAs. It may not know that yet, but it will. (Consultant V)

With regards to the other consultants, I'm not under them but I' $m$ helping out in clinic if they're short staffed... there's been times where they might not have their SHO or any interns, so I will go down to surgery again and assist with their registrar or with their consultant. (PA 1)

Interviewees noted that a specific benefit of the PA is their flexible scope of practice allowing them to assume responsibilities according to fluctuating team needs.

So your autonomy is based on what the consultant needs, what the team needs at the time, and where you fit in. (PA 2)
Most of the PAs explained that although they participate in surgery, their role changes depending on the day and who else is in the operating theater. Many PAs also explained how they develop more skills with more experience and time on their team.

Sometimes I'm first assist in the surgery, sometimes it's just kind of an extra set of hands as well. Over time, the longer I've been on the service, you're kind of building up that trust and developing a skill set surgically as well. So now I'm at the stage where I'm closing or doing surgical techniques as well, and they're really, really encouraging to progress that with you. (PA 5)

Because of this flexibility, consultants and PAs interviewed highlighted how PAs make a positive impact in a variety of settings within the hospital.

It's been incredibly positive and in a very short time... we've basically spread the role out in different areas. So, from clinic, to the operating room, to administration, etc... It's had a hugely positive effect, as we expected. (Consultant V)

\subsection{Lack of role clarity}

Although the flexibility of the PA role affords benefits to the team, consultants believe it also causes some challenges as there is some uncertainty surrounding general definitions and limitations of the PA scope of practice.

Maybe it's just me who's unclear, but maybe we need to be clearer in Ireland about what PAs can and can't do. (Consultant Z)

Consultants noted that it can be difficult to find a balance between the PA's administrative benefits and their important clinical role.

Our big challenge for [our PA] is that she wants more clinical contact... But then we have the flip side, is that we've made the case to the HSE [Health Service Executive] that [PAs] will allow to take some admin roles off the trainees to allow them in theater more. It's hard to balance that. (Consultant W)

I'm a bit weary in Europe and in Ireland that PAs could be used to do different clerical, administrative work and not get enough clinical work or practical surgical work... I have some concern that PAs are viewed in Ireland as, "oh 
here's a great person who can take over all of that administrative side of the team" ... we also need to make sure they have a clinical role. (Consultant Z)

Furthermore, one consultant perceived a lack of communication regarding how other teams within the hospital are utilizing their PAs:

I don't get to meet the other supervisors. The PAs don't get together as a group at any stage... So I actually don't know what the [other specialty] PA is doing... Trying to share information about what the role actually can do doesn't happen. So there seems to be a little bit of a disconnect there. (Consultant W)

Participants of this study agree that physicians at different levels of training have responded to the addition of the PA role differently.

The senior [doctors] have really taken to the role... the SHOs, or the first or second year residents, are trying to find out what her role is, and the interns, who are very junior, go to her a lot for a difficult case or a patient they're not sure about. So it's the middle bit, the portion where she kind of sits, where're they're not quite sure. (Consultant W)

One PA explained how other team members' lack of knowledge on her role as a PA in the hospital can negatively impact her work:

You, yourself, and your consultant, may be very clear on what your scope of practice is but that may not be the case for other people on your team or on other teams... Because I've been in situations where people have thought, "no you shouldn't be doing that because you're not a doctor." But me and my consultant are clear about, "no this IS what I should be doing"... So it's a lack of knowledge about PAs and lack of education about PAs... and people's own personal opinions on the role. (PA 4)

When asked what she would want to change about this PA explained:

Educating other people on what my scope is. That would be the only thing I would want to change...people knowing what it is I'm able to do, what I'm signed off to do, what my consultant has agreed that I can do. That's the only thing that I found can be an issue... but me, personally, I am happy with what I do. (PA 4)

\subsection{Complementary to the medical team}

The consultants explained how after a period of time, the PAs are viewed positively as a well-integrated member of the team.

So initially, there was a little bit of an issue about where [the PAs] actually fit in, but now [our PA] who has been with us, now is completely integrated with the team. (Consultant W)

Given the role's flexibility and continuity, consultants remarked how the PA is better suited for some tasks that have traditionally fallen on residents, such as managing surgical waiting lists. PAs assuming these tasks complements residents' training, allowing more time to train in other areas.

My SHOs are getting to theater much more because a lot of the routine work on the wards, in terms of admissions, in terms of processing patients, that's being done by the PA... So that's been really very welcome by trainees. (Consul$\operatorname{tant} \mathrm{X}$ )

The real benefit is one, I' $m$ more efficient in seeing more patients, and two, the trainee surgeons on my team get to do more operating. That's not to say that [my PA] doesn't actually assist in surgery - when [the residents] are all off on training committees or various assessments, she's there to assist as well. So she's got good flexibility... [PAs] will change the health service in making sure that the right person is doing the right job, which is really complex and there's a lot more to do. (Consultant $\mathrm{Y}$ )

The consultants interviewed explained how PAs streamline their own workflow by facilitating information and task sharing.

They become my eyes and ears on my ward in many ways, identify problems where there are problems, pick up on signs of the possible complications, and simplify my life in many ways rather than having to do a lot of that digging myself. (Consultant Z) 
Consultants expressed how the PA role is complementary to the service as a whole, improving patient follow up and organizing patient care.

I think we're much better organized. I think our interactions with other departments are better. For example, our theater list, we always have patients ready, we know that the patients are worked up, we're much less likely to cancel patients on the day of their admission because an unexpected problem comes to light because those things are being identified at a much earlier time point, and the communication with our scheduling and with our nursing has improved. (Consultant X)

Consultants and PAs remarked that the role of a PA and a resident can overlap in theater, posing difficulties in training both the resident and PA concurrently. However, multiple consultants suggested how a well-trained PA working alongside them would improve efficiency in theater compared to residents.

I would love to have a PA as my first assistant in complex surgery where they get to know the operation really well and it becomes just a welloiled slick machine. Whereas, when I change trainees, I have to start from scratch every year to train them up in the operations, and then by the end of the 6 months they're just getting it and then they move on. (Consultant Z)

\subsection{Regulation and prescribing challenges}

PAs have a flexible scope of practice, completing tasks in a variety of domains, but because the profession is not yet regulated, Irish PAs are not permitted to order ionizing radiation or prescribe.

We can't order X-rays or CT scans or anything with ionizing radiation, [but] we do have the autonomy to book ultrasounds, MRIs. (PA 2)

We have pharmacology classes in college, we know what drugs to prescribe, we just can't prescribe them. (PA 4)

When a patient needs ionizing radiation or a prescription, the PAs said that they report to their consultant or any junior doctor on their team to sign off on the order. Some PAs interviewed said obtaining these signatures doesn't take much time, such as PA 5 who said, "It's not really a hindrance, it just adds a little bit of extra time," while others believe that it can lead to significant delays in patient care.

Published by Sciedu Press
[Patients] can be waiting up until 30 minutes until one of the other doctors is free to come and either write the prescription or order imaging... So it can really delay things from a time perspective. It's happened a few times with me. I'll be hovering in the corridor waiting for someone to be free, and the poor patient is just sitting there. (PA 4)

However, most PAs expressed that having these signing rights in the future would help minimize patient care interruptions, simplify their daily work, and allow greater efficiency.

It would be nice if I had the ability to do that myself just to keep things moving... It would just make things a bit more efficient, I think. (PA 5)

Despite not being able to sign some orders and prescribe, most of the PAs interviewed said they had some role in these aspects of care, such as suggesting which imaging is required or formulating the initial plan to then be confirmed or adjusted by a physician.

The team are very eager for me to practice prescribing and writing down the dose and the route and everything like that, because they want me to practice, because in time they believe we will have prescribing rights. (PA 2)

Even without PA regulation, PAs are still trained and authorized to order other imaging and tests that do not involve ionizing radiation, such as ultrasounds, MRIs, blood type and screens, and arterial blood gases. A few PAs in this study, however, reported problems incorporating these tasks into their work. For example:

We can take arterial blood gases, we're trained to do that, but the machine won't accept our swipe to analyze the result. (PA 2)

Consultants expressed mixed opinions on whether PAs should be able to order ionizing radiation or prescribe medications. Some believed that the utility of the PA is unaffected by the inability to prescribe while others advocate for limited prescribing or prescribing under protocoled pathways.

Whether they'd be able to prescribe doesn't really change very much their use or their functionality. I think that might be an issue if they're out in primary care or if they're independent, but in a hospital setting they are not independent they never see patients on their own...I don't see 
it as an issue to address in the next five years. (Consultant Y)

So I think they absolutely should be able to prescribe. Limited prescribing is probably the best way to start, but the other thing they should be able to do is order non-invasive radiology. Ultrasound, maybe even CT, but no intervention procedures to start with. They definitely should be able to order that kind of stuff. (Consultant W)

Overall, the PAs interviewed expressed that it will likely be years until they are reviewed for professional regulation and subsequently for prescribing privileges.

... to get [prescribing rights] addressed on the grand scheme of things is going to take a long time... it's going to take regulation - to actually enact that change. So I'm trying to not let it affect me on a day to day basis but it's hard. (PA 4)

\subsection{Emerging role of the PA}

The interviewees explained how the new PA role is generally unknown to the Irish public and has low visibility within the medical field.

Unless you've trained in North America, you don't really know what a PA is... It's really all around just letting people know what the role is and how they're here to help... And that they're here to stay. (Consultant V)

While developing the PA profession in Ireland, Consultant Z explained the importance of finding ways to keep the PA role attractive in order to retain PAs long-term, including ensuring possibilities for career advancement as well as appropriate salary for the PA.

The danger in Ireland is that if the reward and the pay is okay but not great, and then if PAs are used just for admin work and don't have a clinical evolution to their work, they won't stay... I think there will be challenges in developing it like it has developed in the States because of those two reasons. (Consultant Z)

[In Ireland] levels of administrative work will be higher, the remuneration will be lower... and Dublin is kind of an expensive kind of city to live in. So on a salary of [the PA] you can't afford to buy a house, you have to commute. It's challenging. (Consultant Z)

Interviewees expected the PA role to continue to evolve in Ireland.

I think there is hope in the next coming years that if - when - the profession is regulated that we will be able to prescribe ourselves going forward. (PA 5)

I could see the PA being there preoperatively with me, planning the procedure, doing the procedure, and follow up care. Absolutely. Down the road, yeah. Definitely assisting in theater. (Consultant W)

Although the scope of practice of the PA may widen in the future, culturally accepting such a scope could take years, one consultant said.

I know in the states, [PAs] are intubating patients, they're running theaters, I just don't think we're at that stage yet... There's lots [PAs] could teach [the residents], but we're just not there, culturally, yet. I think a couple years getting down the road. (Consultant W)

One consultant commented on the possible international implications of the evolving PA role in Ireland:

I'd love us to be able to ultimately be where our graduates could sit for examinations in the United Kingdom, [and] in North America, because for medicine and surgery we can. So why not for the PA role? And that would open up huge collaborative opportunities and huge opportunities in terms of traveling, etc. But I think that this will happen. (Consultant V)

Consultants explained how the PA improves team efficiency and that the biggest challenge with the profession is that there are simply not enough PAs in Ireland and that profession needs to expand.

I see $30 \%$ more patients - we've announced that, we've published that, we've given it to the Department of Health in a document. Things couldn't be better. We actually need to expand... [Our PA] is transformative. We now can't be without her. (Consultant Y) 


\section{Discussion}

In this study, PAs in Ireland are seen as providing much needed continuity of care, which has been positive for patients as well as for consultants and junior doctors. The PA has a flexible scope of practice, is able to adapt to the team's changing needs, and complements the work of the rest of the medical team. The flexibility and novelty of the role, however, can lead to some to perceive a lack of role clarity, both consultants and PAs recognizing a need for improved communication on the PA role within and between medical teams. Because of a lack of professional regulation, PAs may not prescribe medications or order tests involving ionizing radiation. Many of the PAs interviewed believed this authority will be granted in the future, explaining that being able to do so would increase team efficiency and decrease patient wait times. Most consultants supported limited or protocoled prescribing and ordering as appropriate at first, however opinions varied. Because the role is still emerging in Ireland, the PA is still relatively unknown both to the public and within the medical community. The consultants interviewed believe it will be important to keep the Irish PA role attractive as it evolves by supporting the PA's clinical role, providing career advancement opportunities, and ensuring appropriate salary.

An important theme across interviews was the continuity of care the PA role provides for patients and consultants, particularly at times of large-scale changeovers of junior doctors. The continuity PAs provide has been observed in other countries, for example in Germany, where PAs are similarly valued for the continuity they provide to both patients and doctors while residents rotate or leave to participate in surgery. ${ }^{[12]}$ In addition to providing continuity, the PA role builds clinical capacity within the team, helping to improve access for patients, as demonstrated in the Irish pilot projects. ${ }^{[13]}$ PAs are trained as generalists, but also able to be trained for specialist procedures, allowing for a flexible scope of practice to be able to work in any clinical setting. ${ }^{[23]}$ In the US, for example, PAs practice in every specialty with the largest proportions of PAs working in general practice/primary care, surgical subspecialties, and emergency medicine ${ }^{[2]}$ Currently, most Irish PAs work in surgical settings, following the pilot project which involved surgical PAs, however given PAs' generalist training and flexibility they are well-suited to work in other settings. This study reveals how consultants value this flexibility, as PAs can assume responsibilities according to their team's fluctuating needs. Moreover, the flexibility of the role allows PAs to adapt to the changing needs of the healthcare workforce at large. ${ }^{[24]}$

In this study, it appears that the flexibility and novelty of the PA role has led to some lack of role clarity. Consultants questioned how to best utilize the PA's flexible scope of practice, and one PA said some physicians were unaware which tasks the PA is competent in and authorized to perform. Both consultants and PAs suggested that more communication within teams and between different services employing PAs would be helpful in promoting the PA role within a hospital. Other studies have found that a lack of understanding of the PA role hinders PA integration in the workplace. ${ }^{[23,25]}$ The Irish PA pilot evaluation suggested that holding regular meetings and using a variety of educational materials (posters, information leaflets, screen savers) is needed to facilitate staff understanding of the PA role and scope of practice. ${ }^{[13]}$ Developing an outline of the broadly defined Irish PA scope of practice for a given team could be helpful, serving as something the PAs could "fall back on" if their activity is questioned by staff less familiar with the role. One qualitative study in the UK found that although patient participants had poor understanding of the PA role, they were still generally satisfied with their medical encounter with the PA. ${ }^{[26]}$ Similar findings were shown in an Irish study. ${ }^{[20]}$ PAs in the present study expressed how their patients welcomed care provided by a PA.

In addition to establishing role clarity, PAs serving a "niche role" within a team has also been found to facilitate PA integration and retention in settings new to role. ${ }^{[25]}$ After a period of time, the PAs in the present study felt that their role has been well-integrated, functioning as complementary to the medical team. Consultants reported how the PAs could assume various tasks from other team members as well as step in for junior doctors allowing them more time for surgical training, which has also been shown in other international PA research. ${ }^{[27-29]}$ Increasing task-shifting and protectedteaching time for interns has been proposed as two reforms to improve burnout and intern wellbeing in Ireland. ${ }^{[30]}$ The PA has also been shown to benefit consultants, allowing them more time for more complex patients, for outpatients, and for those in the operating room. ${ }^{[31]}$ In short, once integrated, the PA provides a range of medical skills complementary to the existing medical team, supporting the roles of both junior doctors and consultants.

Our findings suggest that Irish PAs experience challenges associated with their lack of professional regulation, which prevents them from prescribing medications or imaging involving ionizing radiation. Similar regulation challenges have been experienced in other countries when introducing the PA role. In the UK, the lack of statutory regulation and prescribing rights has been reported as a major barrier to PA effectiveness ${ }^{[23,31]}$ and was concerning for some physicians who were then held responsible for the PAs. ${ }^{[32,33]}$ In 2018, the UK government announced the introduction of statutory regulation for the PA role, ${ }^{[10]}$ which was a welcome development. Without regulation in Ireland, PAs are not 
permitted to perform some key medical tasks such as prescribing medication and ordering x-rays, which can delay patient care and limit the utility of the PA role. ${ }^{[13]}$ Many of the PAs interviewed thought that this authority would increase team efficiency and decrease patient wait times, many PAs believing that this authority will be granted in the future. Consultants in this study had varying opinions on PA prescribing, but most supported limited or protocoled prescribing or ordering as appropriate at first. It is also important to ensure PAs are practicing at the top of the level at which currently authorized and trained - for example, hospitals can authorize PAs to order other types of imaging and tests, which is permitted despite the absence of PA regulation. To enable effective task-shifting, it is important that any future PA regulation corresponds to the highest level of the PA's training. ${ }^{[34]}$

The PA role is still emerging in Ireland and is being driven by similar factors as in other countries across the world: a shortage of physicians and workforce capacity ${ }^{[13,28,33]}$ as well as a need for task shifting. ${ }^{[34]}$ Thus, PAs are increasingly described as part of the solution to workforce shortages. The conversation on how to best improve healthcare delivery in Ireland continues, with one approach being restructuring surgical teams and exploring the expansion of roles such as the PA. ${ }^{[35,36]}$ The Irish PA has the potential to expand to other settings and has been suggested for use in primary care, ${ }^{[37]}$ which has been described in Ireland as under-sourced and as a crisis situation in the media. ${ }^{[38]}$ In the future as the Irish PA role continues to expand, many consultants in this study believe it will be important to keep the Irish PA role attractive by fostering the PA's clinical role (instead of expanding administrative duties), while providing career advancement opportunities and appropriate salary.

A significant strength of this study is the design, the first of its kind, which involved in-depth in-person one-to-one interviews detailing rich personal accounts of PAs' and consultants' experiences of the Irish PA role. A major limitation of this study is our inability to disclose demographic de- tails about the sample, which would compromise participant anonymity due to the very small population of PAs in Dublin. As a small qualitative study, these results cannot be generalized. However, these results can be used to motivate further research on Irish PAs, such as collecting the experiences of a larger sample of PAs, consultants, as well as junior doctors at sites in both the private and public sectors across a broad geographic area. As the number of PAs in Ireland increases, a follow up survey on these experiences including demographic information would be informative.

\section{Conclusion}

The development of the PA role is in its infancy in Ireland. PAs are valued for their flexible scope of practice and continuity of care they provide to patients and their team, while complementing the work of other medical team members. Facilitating role clarity by increasing communication within hospitals employing PAs may help facilitate PA integration and utility. In order to promote the development of the PA profession in Ireland, securing professional regulation will be key. The Irish PA role is gaining some publicity through webinars, publications, and the PA graduates themselves who serve as ambassadors to the profession in Ireland. Going forward, however, it will be important to improve awareness of PAs both publicly and within the medical community, which could be advanced by physician advocation of the role. Now is the time to explore task shifting within the wider health service in Ireland, using the existing evidence on how PAs can complement other medical roles while improving delivery of care for patients.

\section{ACKNOWLEDGEMENTS}

The authors thank Denni Woodmansee for his support, the Royal College of Surgeons in Ireland for accommodations, PAs for Global Health for partial travel funding, and all participants for their involvement.

\section{Conflicts of InTERest Disclosure}

The authors declare no conflicts of interest.

\section{REFERENCES}

[1] History of the PA Profession and the American Academy of PAs [Internet]. AAPA. [cited $2020 \mathrm{Jul}$ 25]. Available from: https: //www . aapa.org/about/history/

[2] National Commission on Certification of Physician Assistants. 2019 Statistical Profile of Certified Physician Assistants [Internet]. 2020 [cited 2020 Jul 25]. Available from: https://prodcmsstoragesa .blob.core. windows . net/uploads/files/2019Statistic alProfileofCertifiedPhysicianAssistants.pdf
[3] What is a PA? Learn more about the PA profession [Internet]. AAPA [cited $2020 \mathrm{Jul}$ 25]. Available from: https://www. aapa. org/wha t-is-a-pal

[4] Ballweg R, Rick TJ. Physician Assistants and the Expanding Global Health-Care Workforce. The American Journal of Tropical Medicine and Hygiene. 2017 Sep 7; 97(3): 643-4. PMid:28722636. https: //doi.org/10.4269/ajtmh.17-0176

[5] Hooker R, Cawley J, Everett C. Physician Assistants, 4e: Policy and Practice [Internet]. Philadelphia, UNITED STATES: 
F. A. Davis Company; 2017 [cited 2020 Aug 1]. Available from: http://ebookcentral.proquest.com/lib/stanford - ebooks/detail . action?docID $=4838229$

[6] Eyal N, Cancedda C, Kyamanywa P, et al. Non-physician Clinicians in Sub-Saharan Africa and the Evolving Role of Physicians. Int J Health Policy Manag. 2015 Dec 30; 5(3): 149-53. PMid:26927585. https://doi.org/10.15171/ijhpm.2015.215

[7] History [Internet]. CAPA - ACAM. [cited 2020 Aug 4]. Available from: https://capa-acam.ca/about-pas/history/

[8] Burrows KE, Abelson J, Miller PA, et al. Understanding health professional role integration in complex adaptive systems: a multiple-case study of physician assistants in Ontario, Canada. BMC Health Serv Res. 2020 Dec; 20(1): 365. PMid:32349738. https://doi.org/ 10.1186/s12913-020-05087-8

[9] British Government Recognizes Physician Associate Profession [Internet]. AAPA. 2019 [cited 2020 Aug 1]. Available from: https : //www. aapa.org/news-central/2019/10/british-gover nment-recognizes-physician-associate-profession/

[10] Rimmer A. Physician associates will be regulated along same lines as doctors and nurses. BMJ [Internet]. 2018 Oct 12 [cited 2020 Mar 27]; 363. PMid:30315092. https ://doi .org/10.1136/bmj .k4320

[11] Mahase E. GMC will regulate physician associates, government announces. BMJ. 2019 Jul 19; 14783. PMid:31324607. https: //doi.org/10.1136/bmj. 14783

[12] Hix LR, Fernandes SM. An Initial Exploration of the Physician Assistant Role in Germany: The Journal of Physician Assistant Education. 2020 Mar; 31(1): 42-7. PMid:32004250. https://doi .org/10.1 097/JPA. 0000000000000292

[13] Joyce P, Hooker RS, Woodmansee D, et al. Introducing the physician associate role in Ireland: Evaluation of a hospital based pilot project. JHA. 2019 May 24; 8(3): 50. https://doi.org/10.5430/jha. v8n3p50

[14] McGowan Y, Humphries N, Burke H, et al. Through doctors' eyes: A qualitative study of hospital doctor perspectives on their working conditions. Br J Health Psychol. 2013 Nov; 18(4): 874-91. PMid:23480457. https://doi.org/10.1111/bjhp. 12037

[15] Walsh A, Brugha R. Brain Drain to Brain Gain: Ireland's Two-Way Flow of Doctors [Internet]. RCSI Health Workforce Research Group. 2017 [cited 2019 Dec 17]. Available from: http: //www.healthwo rkforceireland.com/1/post/2017/06/brain-drain-to-b rain-gain-irelands-two-way-flow-of-doctors.html

[16] Working Conditions - Working Time Directive [Internet]. European Commission. 2003 [cited 2019 Dec 15]. Available from: https://ec.europa.eu/social/main.jsp?catId=706 \&langId=en\&intPage $I d=205$

[17] Joyce P. First Irish-Trained PAs Graduate from RCSI [Internet]. Physician Assistant Education Association (PAEA). 2018 [cited 2019 Dec 15]. Available from: https://paeaonline.org/first-irish -trained-pas-graduate-rcsi/

[18] Allen M. How Six Audacious PAs Entered the Profession in Ireland [Internet]. AAPA. 2018 [cited 2019 Dec 15]. Available from: https://www .aapa.org/news-central/2018/11/div ing-into-the-unknown/

[19] Joyce P, Arnett R, Hill A, et al. Patient willingness to be seen by a physician associate in Ireland. IJH. 2018 Jul 10; 4(2): 41. https://doi.org/10.5430/ijh.v4n2p41

[20] Joyce P. Patient Satisfaction with Care as Managed by the Physician Associate or the Doctor as Part of a Pilot Project in Ireland. jhms [Internet]. 2019 Jun 30 [cited 2019 Nov 26]; 2(2). https: //doi.org/10.31014/aior.1994.02.02.40
[21] Mapp T. Understanding phenomenology: the lived experience. Br J Midwifery. 2008 May; 16(5): 308-11. https://doi.org/10.129 68/bjom.2008.16.5.29192

[22] Sundler AJ, Lindberg E, Nilsson C, et al. Qualitative thematic analysis based on descriptive phenomenology. Nursing Open. 2019; 6(3): 733-9. PMid:31367394. https://doi .org/10.1002/nop2 . 275

[23] Szeto MC, Till A, McKimm J. Integrating physician associates into the health workforce: barriers and facilitators. Br J Hosp Med (Lond). 2019 Jan 2; 80(1): 12-7. PMid:30592669. https: //doi.org/10.12968/hmed.2019.80.1.12

[24] Cawley J, Hooker R. Physician assistant role flexibility and career mobility. Journal of the American Academy of Physician Assistants [Internet]. 2010 Aug [cited 2020 Mar 23]; 23(8). PMid:20821905. https://doi.org/10.1097/01720610-201008000-00001

[25] Taylor F, Drennan VM, Halter M, et al. Integration and retention of American physician assistants/associates working in English hospitals: A qualitative study. Health Policy [Internet]. 2020 Mar 16 [cited 2020 Mar 27]; Available from: http://www. sciencedirect.co $\mathrm{m} / \mathrm{science/article/pii/S0168851020300518}$

[26] Taylor F, Halter M, Drennan VM. Understanding patients' satisfaction with physician assistant/associate encounters through communication experiences: a qualitative study in acute hospitals in England. BMC Health Serv Res. 2019 Dec; 19(1): 603. PMid:31455342. https://doi.org/10.1186/s12913-019-4410-9

[27] Dies NF, Rashid S, Shandling MR, et al. Physician assistants reduce resident workload and improve care in an academic surgical setting. JAAPA: Official Journal of the American Academy of Physician Assistants. 2016; 29(2): 41-6. PMid:26818645. https: //doi.org/10.1097/01. JAA.0000476214.34937.50

[28] Drennan VM, Halter M, Wheeler C, et al. What is the contribution of physician associates in hospital care in England? A mixed methods, multiple case study. BMJ Open. 2019 Jan; 9(1): e027012. PMid:30700491. https://doi.org/10.1136/bmjope $\mathrm{n}-2018-027012$

[29] Lee B, D'Souza M, Singman EL, et al. Integration of a Physician Assistant Into an Ophthalmology Consult Service in an Academic Setting. American Journal of Ophthalmology. 2018 Jun; 190: 125-33. PMid:29604282. https://doi.org/10.1016/j . ajo.2018.03. 033

[30] Hannan E, Breslin N, Doherty E, et al. Burnout and stress amongst interns in Irish hospitals: contributing factors and potential solutions. Ir J Med Sci. 2018 May; 187(2): 301-7. PMid:28990151. https://doi.org/10.1007/s11845-017-1688-7

[31] Drennan VM, Halter M, Wheeler C, et al. The role of physician associates in secondary care: the PA-SCER mixed-methods study. Health Serv Deliv Res. 2019 May; 7(19): 1-158. PMid:31162917. https://doi.org/10.3310/hsdr07190

[32] White $\mathrm{H}$, Round JE. Introducing physician assistants into an intensive care unit: process, problems, impact and recommendations. Clinical Medicine. 2013 Feb 1; 13(1): 15-8. PMid:23472487. https://doi.org/10.7861/clinmedicine.13-1-15

[33] Jackson B, Marshall M, Schofield S. Barriers and facilitators to integration of physician associates into the general practice workforce: a grounded theory approach. Br J Gen Pract. 2017 Nov; 67(664): e785-91. PMid:28993304. https://doi.org/10.3399/bjgp17 X693113

[34] De Bruijn-Geraets DP, van Eijk-Hustings YJL, Bessems-Beks MCM, et al. National mixed methods evaluation of the effects of removing legal barriers to full practice authority of Dutch nurse practitioners and physician assistants. BMJ Open. 2018 Jun; 8(6): e019962. PMid:29934382. https://doi .org/10.1136/bmjope n-2017-019962 
[35] Meehan D, Balhareth A, Gnanamoorthy M, et al. Efficacy of physician associate delivered virtual outpatient clinic. Int J Health Care Qual Assur. 2019 Aug 12; 32(7): 1072-80. PMid:31411096. https : //doi.org/10.1108/IJHCQA-09-2018-0233

[36] Addressing healthcare retention crisis through changes to surgical services [Internet]. Royal College of Surgeons in Ireland (RCSI). 2020 [cited 2020 Apr 27]. Available from: https://www.rcsi.com/dublin/news-and-events/news/n ews-article/2020/01/addressing-healthcare-retenti on-crisis-through-changes-to-surgical-services

[37] Joyce P, Woodmansee D, O'Neill JP. The physician associate: a role in Irish healthcare? Forum: Journal of the Irish College of General Practitioners. 2019 Sep.

[38] O'Conner W. GP crisis "will leave 230,000 without basic care" - Independent.ie [Internet]. Independent. 2019 [cited 2020 Apr 27]. Available from: https: //www.independent.ie/irish-news/health/gp-crisis-w ill-leave-230000-without-basic-care-38455395.html 